\title{
Estimating urban lawn cover in space and time: Case studies in three Swedish cities
}

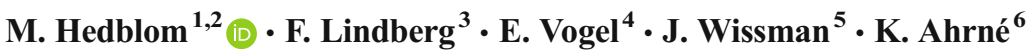

Published online: 24 March 2017

(C) The Author(s) 2017. This article is published with open access at Springerlink.com

\begin{abstract}
Lawns are considered monocultures and lesser contributors to sustainability than diverse nature but are still a dominating green area feature and an important cultural phenomenon in cities. Lawns have esthetical values, provide playground, are potential habitat for species, contribute to carbon sequestration and water infiltration, but also increase pesticides, fertilization, are monocultures and costly to manage at the same time. To evaluate the potential impact of lawns, whether positive or negative, it is of interest to estimate the total lawn cover in cities and its change over time. This is not a straightforward process, e.g., because many lawns are small and covered by trees. In this study we review the existing literature of lawn cover in cities and the different methodologies used for cover estimation. We found both pros and cons with NDVI and LiDAR data as well as manually interpreted aerial photos. The total cover of lawns in three case study cities was estimated to $22.5 \%$. By extrapolating these percentages to all Swedish
\end{abstract}

M. Hedblom

marcus.hedblom@slu.se

1 Department of Swedish Forest resource management, Swedish University of Agricultural Sciences, Skogsmarksgränd, SE-901 83 Umeå, Sweden

2 Department of Ecology, Swedish University of Agricultural Sciences, Box 7044, SE-750 07 Uppsala, Sweden

3 Urban Climate Group, Department of Earth Sciences, University of Gothenburg, Box 460, SE-405 30 Göteborg13, Sweden

4 Department of Physical Geography, Stockholm University, SE-106 91 Stockholm, Sweden

5 Swedish Biodiversity Centre, Box 7016, SE-750 07 Uppsala, Sweden

6 Swedish Species Information Centre, Box 7007, SE-750 07 Uppsala, Sweden cities lawn cover was estimated to $2589 \mathrm{~km}^{2}(0.6 \%$ of the terrestrial surface). The approximated total municipal management cost of lawns in all Swedish cities was 910,000,000 USD/ year. During 50 years lawn area almost doubled in relative cover and $56 \%$ of them were continuously managed. Since lawns constitute large parts of the urban greenery and are costly to manage it is highly relevant to consider their social, ecological and cultural value compared to alternatives, e.g., meadows with less intensive management.

Keywords LiDAR · Orthophoto · Grassland · Meadow · Turf $\cdot$ Management

\section{Introduction}

The existing research of urban green areas and their sizes, qualities and areal changes over time have been focusing on urban greenery in general and rarely on urban lawns (also called grasslands, turf grass, meadows) although lawns are common in cities all over the world. Lawns are however mostly noticeable in the western world in particular but through modernization processes in, e.g., China there has been a fairly recent rapid increase in the establishments of lawns (Ignatieva et al. 2015).

The lawn has supposedly become such an important component of cities due to the numerous ecosystem services lawns provide (Johnson 2013); e.g., good opportunities for activity as sport fields promotes good health, visual esthetic values that increase well-being, carbon sequestration, urban heat regulation (Wang et al. 2016) area for water infiltration (Armson et al. 2013), noise reduction (Fang and Ling 2003) and as substrate for biodiversity, especially when managed as meadows (Ignatieva et al. 2015). However, lawns also have negative effects due to the high use of pesticides (e.g., $17 \%$ of the insecticides used in USA are used for lawns; Milesi et al. 
2005, but the usage of pesticides vary a lot between different regions of the world), fertilizers, vast water consumption (Runfola et al. 2013) and potentially high management costs. Thus, it is of interest to know the areas of lawns in cities to be able to understand the extent of the potentially positive and negative effects.

The basic problem in estimating size and distribution depend on the fact that lawns are very scattered (small parcels) within the cities. The majority of the existing literature of lawn cover in cities is based on either aerial photos (orthophotos; Akbari et al. 2003; Attwell 2000) or LiDAR data (a surveying method that measures distance to a target by illuminating that target with a laser light, the acronym stands for LIght Detection And Ranging; Han et al. 2014). However, many studies seem to combine different techniques such as aerial photos with other remote sensing data (Robbins 2003; Milesi et al. 2005). Many studies use vague explanations on how lawn areas were defined (Stewart et al. 2009) or equaling lawns with other herbaceous vegetation such as flowerbeds and vegetable patches; (Edmondson et al. 2014). Even detailed studies of urban grasslands such as the one made by Fischer et al. (2013) do not map domestic gardens separately because they are so numerous, scattered and small and thus limits the size to $>500 \mathrm{~m}^{2}$ and, e.g., assume that smaller parks includes grasslands.

Areas of lawns may vary in different urban settings, e.g., residential gardens in the city of Koge in Denmark had $31.4 \%$ lawn cover, single family housing areas $31.8 \%$, high density and low rise houses $43.5 \%$, apartments $35.5 \%$ and city center $31.3 \%$ (calculated from Table 1 in Attwell 2000). Studies do, however, seem to be skewed towards non-public residential areas where residential gardens in Christchurch in New Zealand had 47\% cover (Stewart et al. 2009), in the city of Sacramento in USA 24.5\% (Akbari et al. 2003), in Sheffield in U.K. $41.5 \%$ of the gardens had $>75 \%$ cover of lawn (Gaston et al. 2005). Robbins (2003) estimated total cover of lawns in private lots on a larger scale (Ohio county in U.S.A) to be $23 \%$. They (Robbins 2003) used black and white aerial pictures of 63 gardens removing tree cover, garden cover (supposedly e.g. flower beds), sidewalks, driveways, porches and considered the remaining area as lawn and extrapolated this onto state size of lots. Milesi et al. (2005) is the only study, to our knowledge, that estimated total cover of lawns in one country (of all types of urban settings). They (Milesi et al. 2005) used an indirect approach removing impervious surfaces, trees and other undeveloped areas and assumed surface of turf grass to be the inverse of that area. Milesi et al. (2005) used a combination of nightlight measures to estimate impervious surface in combination with aerial photos along transects in 13 major urban centers which later were extrapolated to the whole of USA. The results revealed turf grass on $1.9 \%$ of the total area of USA (approximately 163,800 $\mathrm{km}^{2}$ ).

Milesi et al. (2005) argue that turf grass rarely can be identified using satellite data due to low resolutions. However, since 2005 remote sensing techniques, including high intensity of LiDAR data where multilayers of urban vegetation can be detected, has developed a lot (Han et al. 2014). However, Han et al. (2014) argue that LiDAR data need to be validated in field and that laser data varies in intensity and thus also varies in potential to be used for mapping of urban greenery. In a review of satellite remote sensing in urban settings, Patino and Duque (2013) conclude that many scientists working on regional levels remain skeptical that satellite remote sensing will provide useful information on local scales. Thus, despite the available developed techniques the area of lawns still remains difficult to estimate.

Further, few studies investigated lawn continuity over time although lawns are an old cultural phenomenon, e.g., in Western Europe where they date back to medieval times (Ignatieva et al. 2015). Robinson (2012) has, as one of the few, estimated land cover composition change between 1960 and 2000 at parcel level in an exurban residential area in Michigan USA. The study found an increase in residential areas over time, as well as an increase in tree cover, but that lawns became proportionally smaller when parcels became larger (potentially due to the costs of maintenance of fertilization and the intensity of labor). Huang et al. (2014) used Robinson's results to estimate carbon uptake over time. Fischer et al. (2013) found that historical parks have higher species richness than other grasslands in the city suggesting that there may be a positive relationship between continuity in management of lawns and biodiversity.

The overarching aim of this paper is to use and evaluate different methods to estimate urban lawn cover in space and time in urban areas. We extrapolate lawn cover of three cities to estimate total national cover of lawns in Sweden and a theoretical management cost. We test NDVI (normalized difference vegetation index), LiDAR and aerial photos and discuss the potentials of each method for estimating urban lawn cover. We estimate how large proportion of present lawns that have been managed for more than 50 years using black and white aerial photos from the 1960's. Finally we discuss how of present lawn area and the changes over time affect the potentials for different ecosystem services.

\section{Methodology}

\section{Study sites}

Three major cities in Sweden are used as case study cities, Gothenburg (550,000 inhabitants and sized 45,000 ha), Malmö (270,000 inhabitants and sized 7681 ha) and Uppsala (140,000 inhabitants and sized $4877 \mathrm{ha})$. The cities are located in the Southern third of Sweden (South of the river Dalälven), where more than $86 \%$ of the Swedish population lives (Statistics Sweden 2012). These cities are among the four 
largest cities in Sweden (only Stockholm is larger) and are located in different parts of Sweden and in different landscape context. Malmö is situated in an agriculture dominated area in the south, Gothenburg in a forested area with a lot of bare rocks on the west coast and Uppsala is based in a landscape consisting of mixture of forest and agricultural land (approximately 50\% each) in eastern Sweden. They represent potentially different climate conditions and local cultures in management and establishment of lawns (Ignatieva et al. 2015). These three cities are further studied in a major transdisciplinary project about lawns where two urban Multi-family residential housing neighborhoods that are rather unique for Sweden are investigated; Million program Housing and Post war "Peoples home" where approximately $50 \%$ of the Swedish population live (see Ignatieva et al. 2015). In Sweden $85 \%$ of the population live in urban areas (Statistics Sweden 2012).

Public lawns in Swedish cities are managed both by municipalities and private owners. It is common that, e.g., people in multifamily housing own the lawns and manage them but still allow the public to use them. In, e.g., Uppsala the Swedish church and two Universities are major land owners beside the municipality, and manage their own lawns of which all are open for public use. Ownership of urban green areas in Gothenburg (G), Malmö (M) and Uppsala (U) is; Private person $(\mathrm{G}=20 \% ; \mathrm{M}=22 \% ; \mathrm{U}=18.1 \%)$; Official institutes such as municipalities, universities etc. $(\mathrm{G}=56 \% ; \mathrm{M}=54 \%$; $\mathrm{U}=56 \%)$; Stock companies $(\mathrm{G}=10 \% ; \mathrm{M}=9 \% ; \mathrm{U}=9 \%)$; Private or municipal tenants $(\mathrm{G}=7 \% ; \mathrm{M}=10 \% ; \mathrm{U}=10 \%)$; Other or Unknown ownership $(\mathrm{G}=7 \% ; \mathrm{M}=4 \% ; \mathrm{U}=8 \%)$ (from Statistics Sweden 2015). Thus it is difficult to know the area of lawns of an entire city through municipality protocols of lawn area management only. The municipality of Gothenburg manages a lawn area of 427.5 ha, in Malmö 516.3 ha and Uppsala 681.4 ha (information from nature and planning departments in Gothenburg, Malmö and Uppsala). The lawn areas that are municipality managed do not use fertilization or pesticides for maintenance (information from nature and planning departments in Gothenburg, Malmö and Uppsala municipality).

\section{Mapping methods - LiDAR and NVDI}

Light detection and ranging (LiDAR) data is based on illuminating a target with a laser beam, usually within the near infrared (NIR) wave lengths (reflecting a target on the ground that reflects up to e.g. an airplane with device). Each LiDAR return contains an intensity value (0 to 255) which depends on the reflectivity of the surface. Vegetation provides a relatively high intensity value due to its high reflectivity in the NIR wave lengths. The Normalized difference vegetation index (NDVI) is a value that can be calculated from the amount of light reflected in an image band of wavelengths in the near-infrared and red light. The index usually use images from space satellites, and indicates the amount of living vegetation. Normalized difference vegetation index is used for vegetation analyzes. This works because the vegetation often has high reflection in the NIR band and low reflection in the red visible band.

Gothenburg had high intense LiDAR data available and was thus used to test a method for estimating lawn cover. A smaller area $\left(2 \mathrm{~km}^{2}\right)$ of the south central Gothenburg was chosen as a study area for LiDAR and NDVI studies (this area had suburban character, a mixture of multifamily housing and small private houses in Sweden; see Vogel 2014 for details). Orthophoto and LiDAR datasets was provided by the Building and Planning authority of the city of Gothenburg (Stadsbyggnadskontoret). The LiDAR data was collected at a height of $550 \mathrm{~m}$ with a swath angel of $20^{\circ}$. It covered all of the study area and had 13.65 returns per $\mathrm{m}^{2}$, each point with a $0.13 \mathrm{~m}$ diameter footprint (the area of the pulse when it hits the ground). The LiDAR data was classified into 10 classes, where class 1 (unassigned) and class 2 (ground) were of specific interest to this project and was gridded at a resolution of $1 \mathrm{~m}$. Especially class 1 showed after a closer inspection to reflect pulses near ground level or on ground level, indicating potentials for high level of return pulses for lawns.

The orthophotos had a resolution of $0.25 \mathrm{~m}$. The photos contained both IR and visible bands. A vector polygon dataset of all grass areas maintained by the municipality was used as a complement to the analyses. However, the municipality in Gothenburg (and Sweden in general) only manages their own lawns which are a fraction of total urban lawns.

To be able to extract the lawns from the intensity raster (LiDAR), an intensity threshold value was required. Based on manual comparison of the intensity raster and lawns visible on the orthophotos, and distribution of the intensity values of pixels in the municipal maintenance grass areas, the threshold was set to 150 (see Vogel 2014 for details). Since not only grass show intensity values $>150$, but also areas such as white paint on roads and other highly reflective surfaces, it was necessary to find a way to minimize the number of pixels indicating false grass surfaces. To do this, the raster was first run through a Majority filter tool; if a pixel has another value than at least 3 of its 4 cardinal points, the pixel gets the value of these 3 neighbors. In this process, outliers such as single non-grass pixels inside a grass area or grass pixels in the middle of a road, was removed. A region group tool was used, which groups any connecting clusters of pixels of the same value and gives the group a unique ID. To further filter out non-grass areas registered as grass, a grass area threshold value was set at $7 \mathrm{~m}^{2}$ and all groups with an area smaller than this was removed. The threshold was set to $7 \mathrm{~m}^{2}$ after visually comparing the results of different thresholds between $10 \mathrm{~m}^{2}$ and $5 \mathrm{~m}^{2}$ in the study area with the intention of keeping the threshold as low as possible while still removing the majority of non-grass surfaces registered as grass. 


\section{Mapping methods - aerial photos}

In this study we used ArcMap 10.2 and the aerial photos included in the ArcMap background data from May 2015. The map features $0.3 \mathrm{~m}$ resolution imagery in parts of Western Europe (DigitalGlobe). The lawns were manually mapped (polygons) in three gradients from the urban fringe to the center part of the three cities Gothenburg (length of gradient $=10,200 \mathrm{~m}$ ), Malmö (length of gradient $=7000 \mathrm{~m}$ ) and Uppsala (length of gradient $=5100 \mathrm{~m}$; see Fig. 1). Gradients were located to cover largest possible length of urban areas, not crossing major rivers or lakes and leap in different directions (south-north in Gothenburg, east-west in Malmö and north-south in Uppsala). Four ha squares were interpreted every $500 \mathrm{~m}$ making the total interpreted area in all three cities 132 ha $(N=33$ squares $\times 200 \times 200 \mathrm{~m})$. In Gothenburg $n=15$ squares, Malmö $n=10$ squares and Uppsala $n=8$ squares.

All three cities have an outer border (urban fringe) defined by the statistics Sweden (Statistics Sweden 2013) and were clearly visible in the photos. The center (end) of transects were the medieval inner cities (e.g., in Uppsala the center is in the Castle originally built in 1549 A.D.). Prior to aerial photo interpretation a pretest using drones with high resolution photos was made showing that ArcMap background data had lower resolution but still enough for the purpose of interpreting lawns (i.e., drones would not add additional important information of lawns at the scale of cities but perhaps for local, in detail, studies of single urban green areas).

In each 4 ha square the total area of lawn, meadow (grass that according to municipalities in Sweden are only cut once or twice a year, information from nature and planning departments in Gothenburg, Malmö and Uppsala municipality), sport lawn (soccer fields), trees, shrubs, gravel (sport fields with gravel), bare rock (mountain rocks, very common in Gothenburg), bare soil, water, agricultural fields, bare soil and allotments (small scale gardening) were mapped. Land cover not classified as any of these categories was considered infrastructure (e.g., roads, houses, parking lots, industrial areas etc.). Subsamples of some areas in Uppsala were visited in the field to confirm cover under trees. In areas available for everyone, such as around churches and parks the areas underneath the trees were often (not always) covered by lawns. When some areas were hidden by shadows or trees Google earth street view was used to get an overview of the area. This was mainly done for areas shadowed by houses and trees in all areas except for gardens since it was difficult to see due to hedges and shrubs.

To investigate land-use and lawn cover in historical maps the same 4 ha squares were manually interpreted using black and white aerial pictures from Lantmäteriet (Swedish authority for property registration and geographical information). The photos varied in age between 1956 and 1963 depending on city

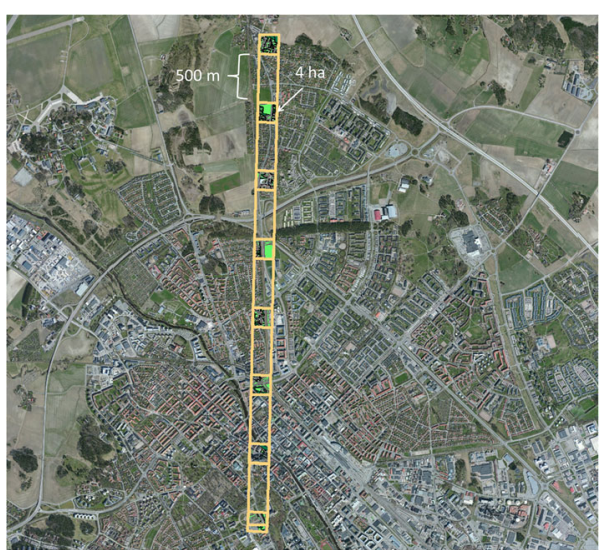

Fig. 1 Illustrates the methodology of how interpreted squares were chosen in the cities, Here illustrated by Uppsala city. The gradient of $N=8$ squares $\left(200 \mathrm{~m}^{2}, 4 \mathrm{ha}\right)$ reaching from the urban fringe (upper corner) to the center of Uppsala (lower part of photo)

and location along the gradients, but will hereafter be referred to as the 1960's photos (although in some cases dating further back). The orthogonal projections of aerial (ortho) have a resolution of $0.5 \mathrm{~m}$ (local variations may apply depending on flight height). Photo shooting took place mainly from $4600 \mathrm{~m}$ above sea level with scale at around 1:30,000 where scanning was made with $15 \mu \mathrm{m}$ providing a resolution of $0.5 \mathrm{~m} /$ pixel.

Present cover that overlapped with cover in the 1960's was considered to be continuity lawns.

\section{Results}

\section{LiDAR and NDVI}

Using LiDAR a significant number of pixels indicated grass although located at roads where there is no grass in reality (for details see Vogel 2014). After filtering and limiting smallest grassland to $7 \mathrm{~m}^{2}$ a lot of "road" grass disappeared. In the investigated area of 430.3 ha 56.9 ha were detected as grass, i.e. $13.6 \%$. The IR (NDVI) captured vegetation very well but had major faults in distinguishing grass from shadows (see Fig. 2).

By comparing the municipally managed areas (with rather precise cover of lawn) with LiDAR data the results showed that the LiDAR detect about $42.6 \%$ of the total municipal lawn areas, the rest of the existing municipal lawns were classified as forests. Thus, LiDAR detected $13.1 \%$ although in this subsampled areas of Gothenburg it should be closer to $31 \%$ (Vogel 2014).

\section{Lawn cover in three cities}

Using manual interpretation revealed similar problems as the LiDAR data revealing that it was difficult to estimate lawn cover under deciduous trees. However, in contrast to LiDAR many of the aerial photos of the cities were taken prior to 
Fig. 2 Detailed comparison of filtered LiDAR-based grass raster and NDVI raster. (a) show the basic orthophoto. (b) show the orthophoto overlaid by the

filtered LiDAR based raster. (c) show the NDVI raster. The red circles indicate areas of interest. It is apparent from looking at all 3 circles that NDVI, in contrast to LiDAR, does not capture vegetation in shaded areas. When comparing (A) and (C) it can also be noted that it is hard to distinguish trees from grass in (C), (d) shows the intensity of LiDAR (modified from Vogel 2014)

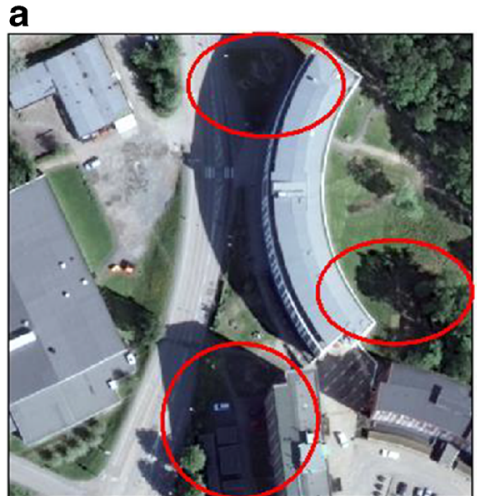

C

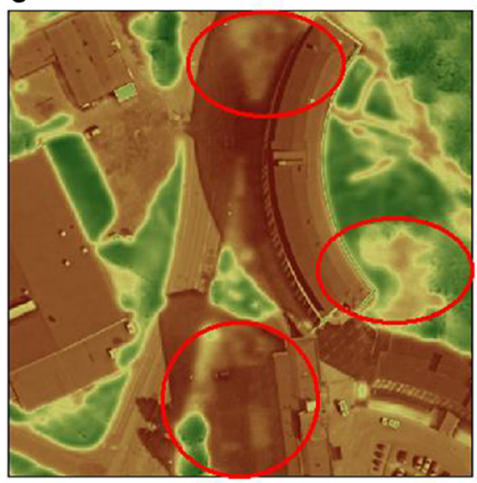

NDVI (C)

Lidar based
1 Grass b

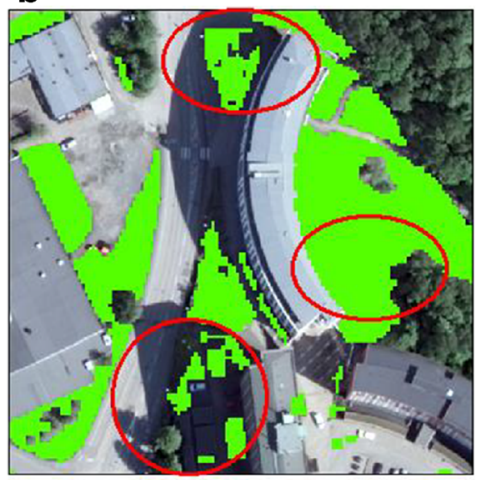

d

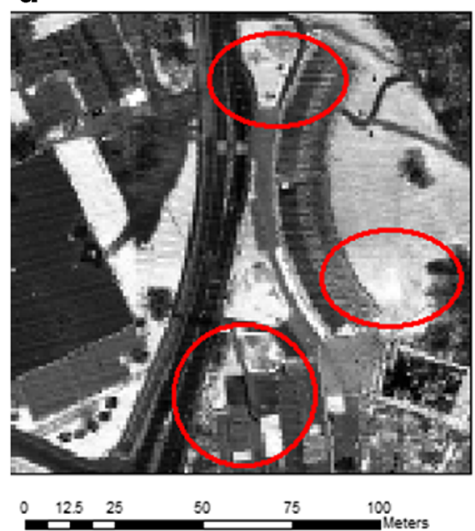

Lidar intensity (D)

Value

High: 25 leafing (May) which meant that it was possible to see the potential lawn cover under deciduous trees. Further, field visits and Google earth street map view helped in interpreting the maps in some situations. However, when there was coniferous trees (not revealing the substrates underneath) the area was interpreted as tree cover and not lawn.

The total cover of lawn in percent, based on a mean of all three cities was in 2015; 22.5\%. In Gothenburg $15.0 \%$ (equivalent to 6750 ha lawn), in Malmö 20.5\% (equivalent to 1578 ha lawn) and Uppsala 31.9\% (equivalent to 1557 ha lawn). If merging all city area and lawn areas together (giving Gothenburg substantial relative more weight in the test since it has 15 transects) the total lawn area would be $20.8 \%$. The lawn cover varied a lot between cities and along the gradients depending on the dominating type of housing areas (Fig. 3). Since the gradients were randomly positioned it was difficult to estimate the specific type of urban setting (e.g. residential areas, churchyards, parks etc.) affecting lawn cover along the gradient (in many places residential areas and multifamily housing were located together) although a general pattern was that lawn cover decreased along the gradient (Figs. 3 and 4). The lawns consisted of three different types, lawn $(16.5 \%)$, meadow $(3.3 \%)$ and sport lawn/soccer field (1\%) in all cities combined.
The total cover of lawn in percent in 1960, based on a mean of all three cities was $12.6 \%$. (Gothenburg 13.8\%, Malmö $6.1 \%$ and Uppsala 17.8\%). Here, the much lower cover of lawn partly depends on higher proportion of agricultural areas and allotments in the 1960's. (see Fig. 5 and Continuity of lawns below). Due to the low resolution of the black and white photos, taken 1960, it was difficult to distinguish meadows from lawns.

Based on our lawn estimations of each city, lawn consisted of $51.8 \%$ of the total green cover in these three cities (based on green cover estimation in Statistics Sweden 2015 which does not define lawns in specific). Thus, of all green areas in Gothenburg 52.5\% was lawn, in Malmö 44.3\% and Uppsala 58.9\%.

\section{Total lawn in Sweden}

Since the LiDAR data missed approximately $57.4 \%$ of the "true" cover of lawns when comparing with the precise data from the municipality management plans, manual aerial picture interpretation was used to estimate cover of lawns in cities instead. Total urban land in Sweden is 1,150,450 ha (Statistics Sweden 2013) and assuming that the $22.5 \%$ cover of lawn is representative for all cities in Sweden results in a total area of lawn of $258,851 \mathrm{ha}\left(2589 \mathrm{~km}^{2}\right)$. This represents $0.64 \%$ of the 
Fig. 3 Cover of lawn in each of the three cities along a gradient from urban center to the urban fringe in 2015. $\mathrm{G}=$ Gothenburg (total distance of gradient is $10 \mathrm{~km}$ ) have 15 squares $\mathrm{M}=$ Malmö $(6.5 \mathrm{~km})$ have 10 squares and $\mathrm{U}=\mathrm{Uppsala}(5.1 \mathrm{~km})$ have 8 squares

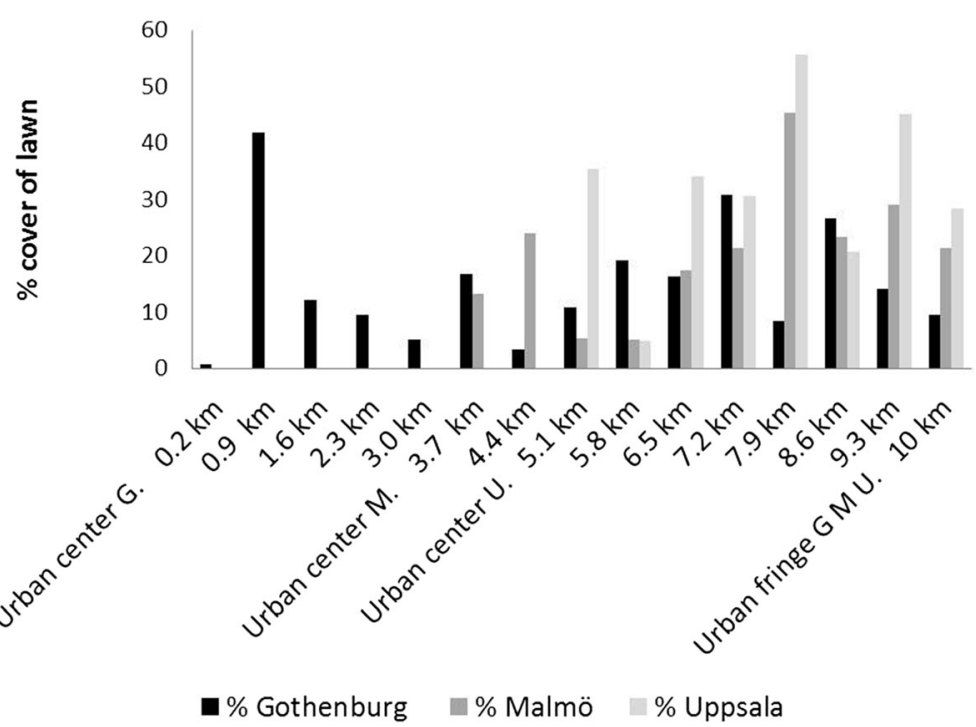

Swedish terrestrial surface $\left(2589 \mathrm{~km}^{2} / 407340 \mathrm{~km}^{2}\right.$; Statistics Sweden 2013). However, large parts of the mapped areas were covered by coniferous forest, thus it was difficult to detect if lawns were underneath (even when using Google earth street view). If assuming the proportion of grass underneath is similar to the undetected lawns found under trees in Gothenburg when municipal management maps were used in Vogel (2014) would add $8.3 \%$ lawns in Sweden. Thus, that would increase the lawn estimation in cities to $30.8 \%(22.5 \%+$ $8.3 \%=30.8 \%)$ with an area of 354,339 ha $\left(3543 \mathrm{~km}^{2}, 0.9 \%\right.$ of terrestrial surface). If all tree cover equaled lawn cover, the total terrestrial cover would be $407,259 \mathrm{ha}\left(4072 \mathrm{~km}^{2} ; 1 \%\right.$ of terrestrial surface) but the true value is probably somewhere halfway (see discussions). No records of lawns underneath shrubs have been reported from any of the cities, thus we treat shrubs as totally lawn free areas.

\section{Continuity of lawns}

$12.6 \%$ of the urban land is lawns with a continuum of at least 65 years. Thus $56 \%$ of the lawns in 2015 were equal to the ones in $1960(12.6 \% / 22.5 \%=56 \%)$. However, the outer 5 of the 15 squares in Gothenburg were agricultural areas or forest in 1960 and thus without lawns (Fig. 6). The patterns of continuity of lawn are difficult to compare along the gradients since the gradients were of different lengths in each city.

If all urban fringes in the 1960's are merged together (Fig. 6) the patters of continuity over the gradient resembles with highest continuity of lawns in the outer borders of the cities and lower towards center Uppsala center is an exception where the final square is in a botanical garden making the continuity of grass very high.

\section{Management and costs}

The total lawn cover estimated in this study was 9885 ha based on $22.5 \%$ coverage. Thus, on average $16.3 \%$ of the lawns in these cities are managed by the municipalities (in Gothenburg 6.3\%, Malmö 32.7\%, Uppsala 43.8\%), the rest are privately managed.
Fig. 4 Illustrating three areas in the outer fringe of southern Gothenburg in 2015 on the left (upper square industrial area, middle multifamily housing and lower shows private houses) and the very same area in the 1960 's where no houses or industry areas exists (only forests or agricultural areas)
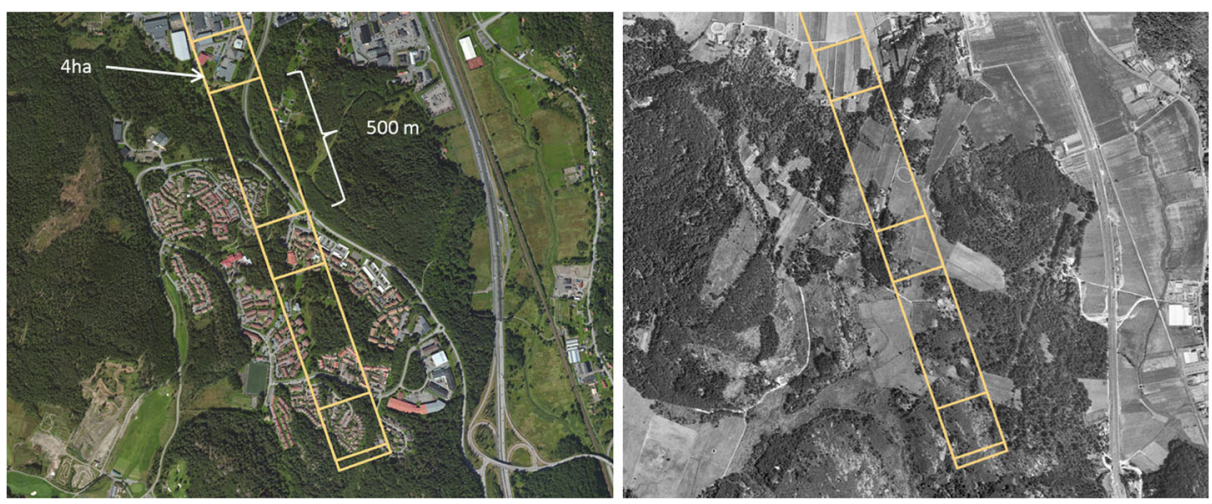
Fig. 5 Average land use cover of each of the three city areas in Gothenburg, Malmö and Uppsala in 2015 and in 1960. "Lawn" consists of all grassland types found in cities such as lawns, meadows and soccer fields. "Bare rock" is mainly occurring in Gothenburg. "Other" consist of areas that seemed to be gravel or bare soil

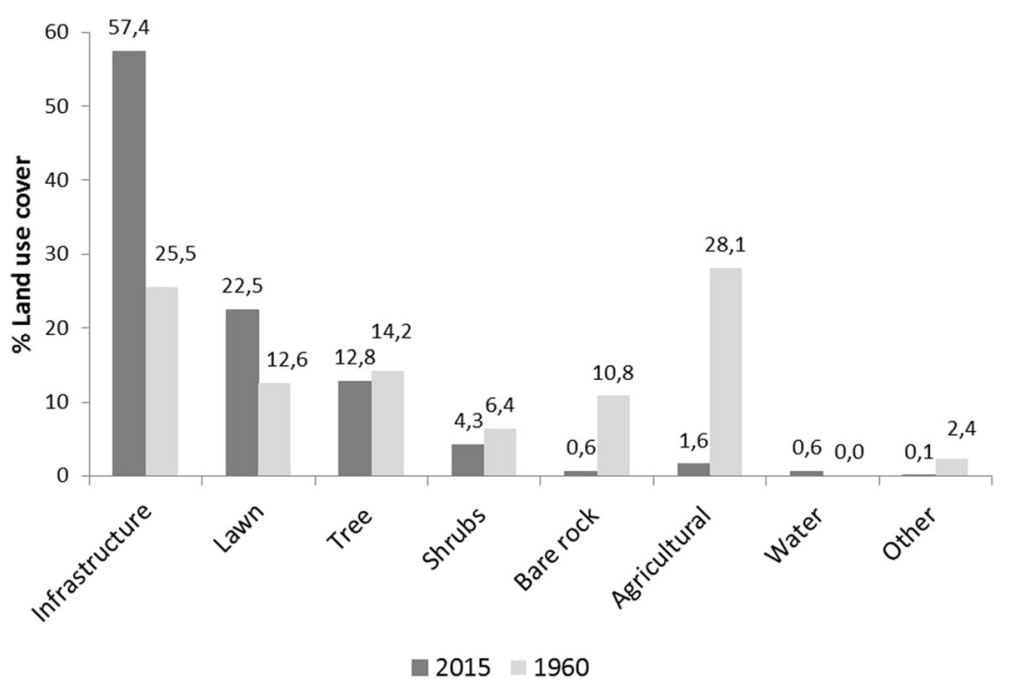

The costs of managing lawns in Gothenburg is 27,368 SEK/ha (3234 USD/ha), in Malmö it is on average 39,261 $\mathrm{SEK} /$ ha (4640 USD/ha) and in Uppsala $9601 \mathrm{SEK} / \mathrm{ha}$ (1134 USD/ha) (information from the Park and Nature department of each municipality). The average costs of all three cities is then $32,336 \mathrm{SEK} /$ ha (3822 USD/ha). Thus, the management costs of lawns in all Swedish cities would be $8.37 \times 10^{9} \mathrm{SEK}(32,336 \mathrm{SEK} / \mathrm{ha} \times 258,851$ ha $)$ which is approximately $9.10 \times 10^{8} \mathrm{USD} /$ year. The management costs only include cutting and maintaining lawns (dressing by occasionally adding soil and by cutting leaves in autumns) and not additional fertilization, no watering or pesticides since municipalities in Sweden do not use them.

\section{Discussion}

\section{Total lawn cover in cities}

The estimate of lawn cover with our method was on average $22.5 \%$ of the total city area and if extrapolated, $0.6 \%$ of the total terrestrial surface of Sweden (compared to USA where lawn was estimated to cover $1.9 \%$ of the area; Milesi et al. 2005). Although mapping was made in aerial photos prior to leaf setting on deciduous trees it was still not possible to detect lawn under coniferous trees (unless seen by Google earth street view or field visits). Some areas were found to be forests with barerock and no undercover vegetation (especially in Gothenburg), thus making lawn cover and total tree cover ratios equally was
Fig. 6 The lawns cover along an urban gradient from the urban fringes to urban centers in 1960 in three cities. The urban fringe and centers in Malmö and Uppsala were the same in 1960-2015 (the gradient distances were the same, 8 respectively 10 squares). The urban fringe in Gothenburg was $3.5 \mathrm{~km}$ further out in 2015 (10 squares in 1960 and 15 squares in 2015)

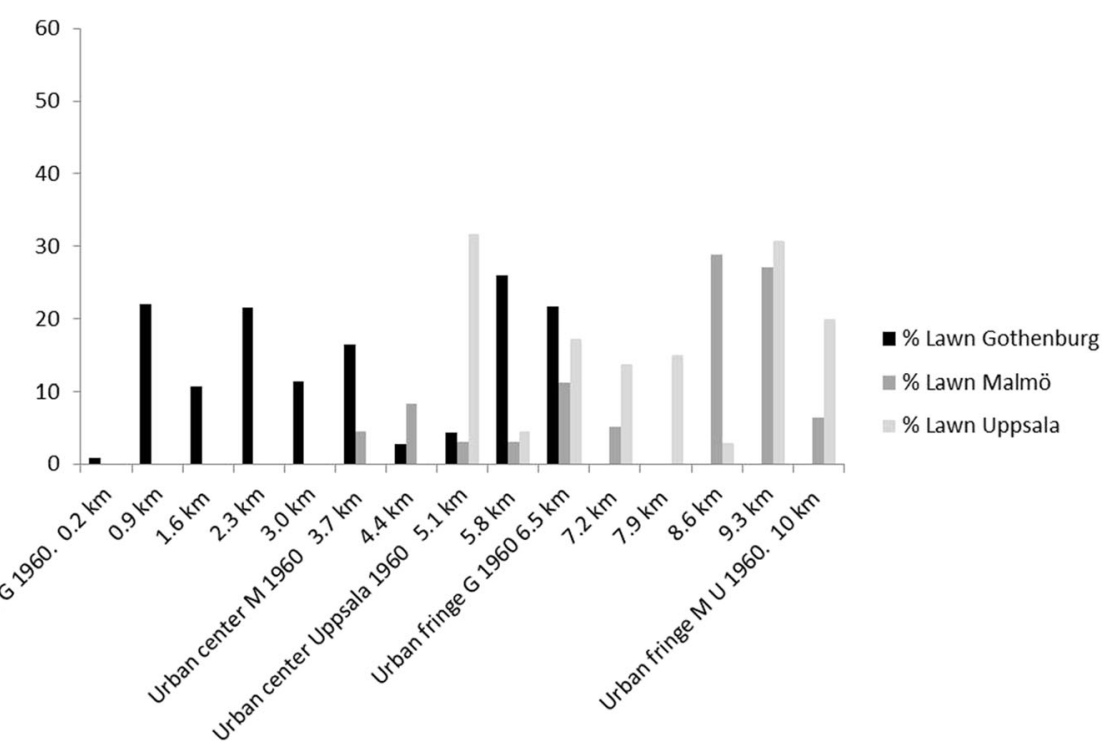


not an option. However, most probably some of the mapped trees had lawn underneath and thus the lawn cover would most accurately be described as between $22.5 \%$ and $30.8 \%$ (0.6$0.9 \%$ of total terrestrial land use in Sweden).

The national cover is rather speculative since we only use subsamples of three cities $(0.2 \%$ of total urban area in Gothenburg, $0.5 \%$ in Malmö and $0.7 \%$ in Uppsala) and the variation of lawns is supposedly substantial between different locations in each city and also different locations in Sweden depending on urban development and size of cities. However, total areas of the case study cities are $6.1 \%$ of the total urban cover in Sweden (based on Statistics Sweden 2012) and these cities are further presumably rather representative for urban green cover in the cities in southern Sweden $(>86 \%$ of the population live) due to that their locations in three different dominating landscape types.

Comparisons between cities within Sweden and in other countries are difficult because many studies only focus on single cities or parts of the cities. If we assume that the $1.9 \%$ lawn cover in Milesi et al. (2005) was representative for cities in USA the lawn cover would be $42 \%$ (based on an urban cover of $4.5 \%$ in USA). Thus, it might be possible that the urban lawn cover in USA is twice in cities although the explanation could be due to that cities or urban areas were not clearly defined in Milesi et al. (2005) and presumably conditions that not exists in Sweden (such as low urban density and large parcels in urban sprawl areas) were included in their study.

\section{Different methodologies and tree cover}

In this study we used both LiDAR data and manually interpreted aerial photos. Each method has its pros and cons. LiDAR can easily detect numerous small and scattered lawn areas over large areas with low effort in time which contrasts the labor intensive digitizing of lawns manually (Robinson 2012) from aerial pictures. However, the methodology of LiDAR setting e.g., linking lawn to different intensity could initially be time consuming. The intensity of the LiDAR further varied quite much in the larger scale (of the entire city of Gothenburg) which depended on inaccurate calibration between the collection events (Vogel 2014). This meant that it was not possible to use the same grass thresholds (a value of $>150$ where grass was detected) for the whole of Gothenburg and further the data was separated into tiles making it impossible to manually set different intensity thresholds. This could however be avoided if the operators of LiDAR made intensity more even. A major obstacle with LiDAR was the difficulties in detecting lawns underneath trees with detection rate as low as approximately $43 \%$. However, we see large potentials in further developing a grass area identification LiDAR model including estimations of grass covered by trees.

The manual photo interpretation method makes it possible to detect variations in the landscape and rather exact map lawn borders. In our case we could also use photos that revealed grass under trees to a large extent. However, it is time consuming to manually make polygons of each small lawn (approximately 4500 polygons in this study), and in addition LiDAR data is objective as opposed to aerial interpretation which is a subjective evaluation of borders and features. As for the black and white photos from the 1950s and 1960s the resolution made it difficult in some cases (not all) to detect differences between shrubs versus trees and lawns versus potential garden plots (in figures merged to "allotments").

Thus, using LiDAR in our study underestimated lawn cover due to shade effects and tree cover. Tree cover is handled very differently in studies of lawns. Huang et al. (2013) used LiDAR and IR (infrared) orthophotos in a 300 ha area in Shanghai (China) to develop an automated method for calculating total urban green volume where all green areas not classified as trees were considered to be grasslands. Milesi et al. (2005) had an opposite approach assuming that tree cover was equivalent to lawn cover. However, in the case of Milesi et al. (2005), this might provide an overestimation of lawns since, e.g., studies in USA showed that in non-residential areas $50-70 \%$ of the areas under the canopies were paved surfaces and $35 \%$ in residential areas (Akbari et al. 2003). This bias of potential overestimation due to tree cover is especially pronounced if cities with large areas covered by such trees as in Northeastern USA where on average one third of urban land is covered by trees (Dwyer et al. 2000). This illustrates the problem with estimating true lawn cover in relation to trees.

Due to the labor intensive mapping we used a subsample of 4 ha areas along gradients and not total cover. Gradient analyses are to some extent questioned since cities of today does not clearly have a center and a border but are conglomerates where smaller cities are merged into each other (McDonnell and Hahs 2008). However, Swedish cities in general and these three cities in particular, do have clear urban fringes and defined medieval city cores.

The semi-objective sampling using 4 ha every half $\mathrm{km}$ is supposedly better than subjectively defining housing typologies since the borders of the housing area sets the limits for lawn estimations. For example, in a study investigating three typologies of housing in Sweden (residential gardens and two types of multifamily housing areas) the average cover of lawns were $27.8 \%$ (5.3\% higher than in this study; Ignatieva et al. 2017).

\section{Land use of lawns along gradients}

Lawn cover varied between cities (15-32\%) and along the gradients (5-55\%) in 2015 (Fig. 3). General patterns along the gradients were that cover declined towards the city centers (in Gothenburg not as evident as in the other cities). This is most probably because cities in Sweden are denser 
towards the center. However, some clear exceptions are seen in Fig. 3 where high peaks in the center of Uppsala are due to a botanical garden and a high peak close to the center of Gothenburg is a major urban park. The general pattern of housing types along gradients was; residential areas and industrial areas in the fringes followed by multifamily housing (often highest coverage of lawns) and closer to centers with dense multifamily housing.

The lower cover of lawns in Gothenburg (7.5\% lower than average) could be explained by large parts of bare rock (due to Gothenburg's location close to sea) and that it as a major city (with approximate 500,000 inhabitants) includes many industrial and densely populated areas along the gradient. An explanation to the high cover of lawns in Uppsala (9.4\% higher than average) could be that the gradient did not cover any industrial areas or that it included multifamily housing areas such as the million program housing known for high lawn coverage.

Lawn cover along the gradient in the 1960's was much lower than in 2015 (Fig. 5). This is most probably due to a higher proportion of agricultural areas along the gradients. Further, it seemed as numerous residential areas had more garden plots (allotments in figures) or bare soil (bare soil was typology "other" in Fig. 5). Surprisingly, in Gothenburg, some places having bare rocks in 1960 had residential areas with lawns in 2015.

\section{Continuity of lawns}

$56 \%$ of the lawns (or meadows) in Swedish cities in the 1960 's remained lawns $50-60$ years later $(12.6 \%$ of the average cover of lawns in cities 2015 were the same as the ones in 1960). The highest cover of lawns with long continuity was found in all three urban fringes in the 1960's which resembles the patterns of lawns in 2015. As visual sized by the photos from 1960 many residential areas had allotments/garden plots instead of lawns and many gardens has since the 1960's densified and added one or more houses in the same garden reducing original lawns.

Since all three cities are old (at least a 500 years e.g. Uppsala have houses dating from 1280 A.D.) some of the present lawns may have been pastures or meadows for much longer than 50 years. The continuity of lawns as grasslands is important to biodiversity since they may have older seedbanks (Gustavsson et al. 2007), e.g., historic urban parks in Berlin have high species richness due to their habitat continuity (Fischer et al. 2013; Maurer et al. 2000). Thompson et al. (2004) found that lawns in cities had relatively well-defined plant communities with a species pool comparable in size to that of semi-natural grasslands. Although not suggested in Thompson et al. (2004) their unexplained higher diversity in lawns further from the city border of Sheffield may have been an effect of long continuity.

\section{Ecosystem services and management}

In Europe (and Sweden as well) there is an outspoken densification trend leading to reduction in available green areas per person (Statistics Sweden 2005) at the same time as new research highlight their importance for ecosystem services (Haase et al. 2014). Lawns in Swedish cities dominated the urban green with more than half of the areas being lawns and thus being potentially important as ecosystem service supporters.

However, management of lawns is costly. Reducing the cutting frequency to once or twice a year could make the lawns more meadow like and potentially provide a higher species richness of plants and butterflies and increase public enjoyment (Garbuzov et al. 2015). Already today 3.3\% of the lawns were less often mowed (meadow typology). With longer continuity and low frequencies of mowing, in combination with removal of the grass-cuttings, existing grasslands could get more similar to semi-natural grasslands. It is obvious that urban lawns and meadows have an important role to play in the future landscape when it comes to grassland biodiversity. It is important to educate decision makers and practitioners of the connection between management for biodiversity and for beneficial ecosystem services. The management costs for lawns in this study varied highly between cities where e.g. Malmö had almost 4 times higher costs than Uppsala per hectare, this large variation should be further investigated.

The trend of increased densification of cities reduce availability of urban green per person in Gothenburg from 281 to $272 \mathrm{~m}^{2}$ per persons during 5 years (exemplified year 2000 2005), in Malmö 154-153 $\mathrm{m}^{2}$ and in Uppsala $261-251 \mathrm{~m}^{2}$; Statistics Sweden 2005). Urban green is used for recreation and important to human well-being. However, lawns are not considered being as high contributors to well-being as forests (Tyrväinen et al. 2014) and more nature like areas (Ode-Sang et al. 2016). Studies even show not even private house lawns are seldom used (Norlin and Wissman unpublished).

Since lawns constitute such large part of the green areas in cities they are also an important part of the urban green areas citizens encounter in their everyday life. Thus, it is crucial for an ever increasing urban population to fully consider the social and ecological value and constraints of lawns. Finally, in order for decision makers to value lawns for their ecosystem services in relation to other urban green areas and the increasing need of green infrastructure reliable methods to measure lawn area and changes in time are important.

\section{Conclusions}

The methodologies tested in this study both had pros and cons. LiDAR data was very low in labor intensity (once the semiautomated procedure was established) while manually 
interpreted aerial photos took long time handling. Aerial photos enabled good detailed accuracy as for estimating borders and sizes of lawns while LiDAR made automatic estimations that sometimes included shadows and roads. The manually made polygons of lawn also have drawbacks since they are based on the interpreter's subjective interpretation in aerial photos while the estimates using LiDAR are objective. Major obstacles were how to do estimates of lawn cover beneath trees. LiDAR severely underestimated lawn cover under trees and aerial photos made it possible to find photos taken prior to leaf in spring. However, we predict that the future lies within LiDAR where new models will be able to identify estimations of grass overgrown by trees.

The estimated lawn cover was estimated to be between $22.5 \%$ and $30.8 \%(0.6-0.9 \%$ of total terrestrial land use in Sweden) depending on forest cover. Approximately $56 \%$ of the lawns were managed during the last 50 years. The yearly cost of managing lawns in the whole of Sweden (based on approximation of lawn covers of three cities and their average lawn cost per ha) was $9.14 \times 10^{8}$ (USD per year). Half of the urban green areas in cities constituted of lawns. Thus, it is important to consider social, ecological and cultural values of lawns compared to alternative urban greenery or alternative management of lawns as e.g., meadows with less intensive cutting regimes.

Acknowledgements This study was funded by Formas, the Swedish Research Council for Environment, Agricultural Sciences and Spatial Planning (225-2012-1369, 259-2012-887 and 214-2010-1706). We are grateful to the nature and planning departments in Gothenburg, Malmö and Uppsala municipality for providing management costs of lawns and also the building and planning authority of the city of Gothenburg (Stadsbyggnadskontoret) for providing LiDAR data. We would further like to thank Merit Kindström for valuable GIS support and Lena Gustafsson for providing high resolution photos using drones, both at the department of Ecology at the Swedish University of Agricultural sciences. Finally we thank the anonymous reviewer who contributed with important comments that substantially improved the manuscript.

Open Access This article is distributed under the terms of the Creative Commons Attribution 4.0 International License (http:// creativecommons.org/licenses/by/4.0/), which permits unrestricted use, distribution, and reproduction in any medium, provided you give appropriate credit to the original author(s) and the source, provide a link to the Creative Commons license, and indicate if changes were made.

\section{References}

Akbari H, Shea Rose L, Taha H (2003) Analyzing the land cover of an urban environment using high-resolution orthophotos. Landsc Urban Plan 63:1-14. doi:10.1016/S0169-2046(02)00165-2

Armson D, Stringer P, Ennos AR (2013) The effect of street trees and amenity grass on urban surface water runoff in Manchester, UK. Urban For Urban Green 12:282-286. doi:10.1016/j. ufug.2013.04.001

Attwell K (2000) Urban land resources and urban planting - case studies from Denmark. Landsc Urban Plan 52:145-163
Dwyer J, Nowak D, Noble M, Sisinni S (2000) Connecting people with ecosystems in the 21st century: an assessment of our nation's urban forests. General technical report PNWGTR- 490. Portland, OR: USDA Forest Service Pacific

Edmondson JL, Davies ZG, McCormack SA, Gaston KJ, Leake JR (2014) Land-cover effects on soil organic carbon stocks in a European city. Sci Total Environ 472:444-453

Fang CF, Ling DL (2003) Investigation of the noise reduction provided by tree belts. Landsc Urban Plan 63(4):187-195. doi:10.1016 /S0169-2046(02)00190-1

Fischer LK, von der Lippe M, Kowarik I (2013) Urban land use types contribute to grassland conservation: the example of Berlin. Urban For Urban Green 12:263-272. doi:10.1016/j.ufug.2013.03.009

Garbuzov M, Fensome KA, Ratnieks FLW (2015) Public approval plus more wildlife: twin benefits of reduced mowing of amenity grass in a suburban public park in Saltdean, UK. Insect Conservation and Diversity 8:107-119

Gaston KJ, Warren PH, Thompson K, Smith RM (2005) Urban domestic gardens (IV): the extent of the resource and its associated features. Biodivers Conserv 14:3327-3349. doi:10.1007/s10531-004-9513-9

Gustavsson E, Lennartsson T, Emanuelsson M (2007) Land use more than 200 years ago explains current grassland plant diversity in a Swedish agricultural landscap. Biol Conserv 138:47-59

Haase D, Larondelle N, Andersson E, Artmann M, Borgström S, Breuste J, Gomez-Baggethun E et al (2014) A quantitative review of urban ecosystem service assessments: concepts, models, and implementation. Ambio 43:313-433

Han W, Zhao S, Feng X, Chen L (2014) Extraction of multilayer vegetation coverage using airborne LiDARdiscrete points with intensity information in urban areas: a casestudy in Nanjing City, ChinaWenquan. Int J Appl Earth Obs Geoinf 30:56-64

Huang Y, Zhou J, Hu C, Tan W, Hu Z, Wu J (2013) Toward automatic estimation of urban green volume using airborne LiDAR data and high resolution remote sensing images. Front Earth Sci 7(1):43-54. doi:10.1007/s11707-012-0339-6

Huang Q, Robinson DT, Parker DC (2014) Quantifying spatial-temporal change in land-cover and carbon storage among exurban residential parcels. Landsc Ecol 29:275-291

Ignatieva M, Ahrné K, Wissman J, Eriksson T, Tidåker P, Hedblom M et al (2015) Lawn as a cultural and ecological phenomenon: a conceptual framework for interdisciplinary research. Urban Forest \& Urban Greening 14:383-387. doi: 10.1016/j.ufug.2015.04.003

Ignatieva M, Eriksson F, Eriksson T, Berg P, Hedblom M (2017) Lawn as a social and cultural phenomenon in Sweden. Urban Forest \& Urban Greening 472:444-453

Johnson PG (2013) Priorities for Turfgrass management and education to enhance urban sustainability worldwide. Journal of developments in sustainable agriculture 8(1):63-71 . doi:10.11178/jdsa.8.63doi

Maurer U, Peschel S, Schmitz S (2000) The flora of selected urban landuse types in Berlin and Potsdam with regard to nature conservation in cities. Landsc Urban Plan 46:209-215

McDonnell MJ, Hahs A (2008) The use of gradient analysis studies in advancing our understanding of the ecology of urbanizing landscapes: current status and future directions. Landsc Ecol 23(10): 1143-1155. doi:10.1007/s10980-008-9253-4

Milesi C, Running SW, Elvidge CD, Dietz JB, Tuttle BT, Nemani RR (2005) Mapping and modeling the biogeochemical cycling of turf grasses in the United States. Environ Manag 36(3):426-438

Ode-Sang A, Gunnarsson B, Knez I, Hedblom M (2016) The effects of naturalness, gender, and age on how urban green space is perceived and used. Urban For Urban Green 18:268-276

Patino JE, Duque JC (2013) A review of regional science applications of satellite remote sensing in urban settings. Comput. Environ. Urban Syst 37:1-17. doi:10.1016/j.compenvurbsys.2012.06.003

Robbins P, Birkenholz (2003) Turfgrass revolution: measuring the expansion of the American lawn. Land Use Policy 20: 181-194 
Robinson DK (2012) Land-cover fragmentation and configuration of ownership parcels in an exurban landscape. Urban Ecosystems 15: 53-69. doi:10.1007/s11252-011-0205-4

Runfola DM, Polsky C, Nicolson C, Giner NM, Pontius RM Jr, Krahe J, Decatur A (2013) A growing concern? Examining the influence of lawn size on residential water use in suburban Boston, MA, USA. Landsc Urban Plan 119:113-123. doi:10.1016/j.landurbplan.2013.07.006

Statistics Sweden (2005). Changes in green space, within the ten largest localities 2000-2005. In Swedish with English summary

Statistics Sweden (2012) Localities 2010: Population, age and gender. In Swedish with English summary

Statistics Sweden (2013) Land use in Sweden. Sixth edition. In Swedish with English summary

Statistics Sweden (2015) Green space and green areas within localities: 2010 In Swedish with English summary

Stewart GH, Ignatieva ME, Meurk CD, Buckley HB, Horne B, Braddick T (2009) URban biotopes of Aotearoa New Zealand (URBANZ) (I): composition and diversity of temperate urban lawns in Christchurch. Urban Ecosyst 12:233-248

Thompson K, Hodgson JG, Smith RM, Warren PH, Gaston KJ (2004) Urban domestic gardens (III): composition and diversity of lawn floras. J Veg Sci 15:373-378

Tyrväinen L, Ojala A, Korpela K, Tsunetsugu Y, Kawaga T, Lanki T (2014) The influence of urban green environments on stress relief measures: a field experiment. J Environ Psychol 38:1-9. doi:10.1016/j.jenvp.2013.12.005

Vogel E (2014) Mapping grass areas in urban environments: developing a general grass detection model. Degree of bachelor I science at Gothenburg university. ISSN 1400-3821 http://gvc.gu. se/digitalAssets/1503/1503906_b813.pdf

Wang ZH, Zhao X, Yang J, Song J (2016) Cooling and energy saving potentials of shade trees and urban lawns in a desert city. Appl Energy 161:437-444. doi:10.1016/j.apenergy.2015.10.047 